\title{
Anterior chamber aspirate cultures in small incision cataract surgery
}

The Royal Victoria Infirmary, Newcastleupon-Tyne T D Manners D K Chitkara P J Marsh M G Stoddart

Correspondence to: Mr T D Manners, West Norwich Hospital, Bowthorpe Road, Norwich Bowthorpe

Accepted for publication 17 May 1995

\begin{abstract}
Background-Anterior chamber aspirates on completion of extracapsular cataract surgery contain significant numbers of organisms, particularly coagulase negative staphylococci, an important cause of endophthalmitis.

Methods-Culture rates were compared in 50 patients after phacoemulsification surgery, which allows the possible benefits of a small, self sealing wound and maintenance of positive intraocular pressure, with a similar number of extracapsular cases.

Results-A culture positive rate of $20 \%$ and $24 \%$ respectively was found, an insignificant difference.

Conclusion-Small incision surgery has no proved advantage over extracapsular surgery in terms of reducing the intraoperative bacterial inoculum. The significance of this result in terms of causation of endophthalmitis is discussed.

(Br f Ophthalmol 1995; 79: 878-880)
\end{abstract}

Recent studies by this and other groups have confirmed that the anterior chambers of eyes following extracapsular cataract surgery are frequently contaminated by small numbers of bacteria. ${ }^{1-3}$ Contamination rates of $29-43 \%$ have been reported. This group found a rate of $24 \%$ in two groups of 40 patients, and that preoperative topical antibiotics (norfloxacin, MSD) had no effect on culture rates. The organisms found are in small numbers (10-40 colony forming units $/ \mathrm{ml}$ ), and are most commonly skin commensals, especially coagulase negative staphylococci. These organisms are a leading cause of endophthalmitis. It has been assumed that one route of entry is from fluid circulating in the conjunctival sac at the time of surgery, but although both povidone-iodine ${ }^{45}$ and topical antibiotics ${ }^{6}$ are effective in reducing skin commensals (as shown by conjunctival swabs), efforts to sterilise the conjunctival sac preoperatively are only one approach to the problem, and according to our previous work may not be reducing intraocular contamination.

Phacoemulsification allows a smaller wound, and is usually combined with a scleral tunnel which has a degree of self sealing properties. The eye is, therefore, less accessible to contamination from any external source, be it conjunctiva, lashes, or air. Studies of intraoperative pressure changes do suggest that positive intraocular pressure is easier to maintain with this type of wound, ${ }^{7}$ and this, together with the small wound, should minimise influx of conjunctival fluid from the wound margins.

This study has been designed to examine the contamination of anterior chambers of eyes at the completion of phacoemulsification cataract surgery, and to compare this with previous observations from extracapsular surgery.

\section{Materials and methods}

Fifty patients undergoing routine phacoemulsification cataract surgery were recruited into this prospective study. Written consent for aqueous samples to be taken was obtained. Exclusion criteria included: (a) history or evidence of previous surgery or penetrating injury to the eye; $(b)$ local or systemic infection at the time of surgery; $(c)$ perioperative complications such as posterior capsule rupture or conversion to extracapsular surgery.

No preoperative drops other than preservative free cyclopentolate $1 \%$ and phenylephrine $10 \%$ were used. In theatre, aseptic preparation consisted of scrubbing the eyelids, nose, cheek, eyebrow, and forehead with povidone-iodine $7.5 \%$ in concentric circles outwards from the eyelids. The same solution was dropped into the conjunctival fornices and not rinsed. The patient's face was draped with sterile cloths and excess iodine wiped clear. Clear adhesive Steridrape was applied. In all respects up to this point the preparation was identical to our earlier study on extracapsular surgery. Phacoemulsification was performed by two surgeons using the same technique. A $3.2 \mathrm{~mm}$ scleral tunnel and separate paracentesis functioned as entry sites, and fluids used were sterile balanced salt with adrenaline 1:100000 and sodium hyaluronate. A $5.5 \mathrm{~mm}$ one piece PMMA lens was implanted after enlarging the wound and irrigating the lens with balanced salt. All viscoelastic was removed. Following anterior chamber reformation, two sutures closed the scleral tunnel, and $0 \cdot 1-0 \cdot 2 \mathrm{ml}$ of fluid was removed from the anterior chamber with a sterile 27 gauge cannula via the paracentesis. Further reformation was then followed by subconjunctival cefuroxime injected into the superior bulbar area. The aspirate was sealed and taken within 3 hours to the microbiology laboratory. Single drops of approximately $0.025 \mathrm{ml}$ were distributed directly from the syringe to chocolate blood agar (CBA) $\left(5 \%\right.$ carbon dioxide, $\left.37^{\circ} \mathrm{C}\right)$, Todd-Hewitt broth $\left(37^{\circ} \mathrm{C}\right)$, blood agar (ABA) (anaerobic, $37^{\circ} \mathrm{C}$ ) and malt extract agar (MEA, Oxoid, UK) (air, $30^{\circ} \mathrm{C}$ ) in sequence and looped out. If insufficient specimen remained to permit inoculation of the latter two media an equivalent volume of broth was 
Table 1 Details of positive cultures

\begin{tabular}{clll}
\hline $\begin{array}{l}\text { Patient } \\
\text { No }\end{array}$ & Organism & Medium & $\begin{array}{l}\text { No of } \\
\text { colonies }\end{array}$ \\
\hline 2 & Coag negative staphylococcus & CBA & 6 \\
5 & Coag negative staphylococcus & CBA & 1 \\
11 & Micrococcus & CBA & 1 \\
20 & Coag negative staphylococcus & CBA & 1 \\
22 & Coag negative staphylococcus & MEA & 1 \\
29 & Diphtheroid & Broth & - \\
33 & Diphtheroid & Broth & - \\
$37 \dagger$ & Diphtheroid & ABA & 1 \\
$39^{\star} \dagger$ & Gram positive coccus & ABA & 1 \\
$45^{\star}$ & Gram negative diplococcus & CBA & 1 \\
\hline
\end{tabular}

${ }^{\star}$ Lost on subculture. $\nmid$ Broth inoculated medium. $\mathrm{CBA}=$ chocolate blood agar; $\mathrm{MEA}=$ malt extract agar; $\mathrm{ABA}=$ blood agar.

drawn into the syringe, agitated and distributed. The broth was subcultured at 24 hours to $\mathrm{CBA}$ ( $5 \%$ carbon dioxide, $37^{\circ} \mathrm{C}$ ). All cultures were incubated for 5 days and examined regularly for growth. Organisms were identified by standard microbiological methods.

\section{Results}

Fifty eyes were sampled and aspirate volume averaged $0.1 \mathrm{ml}$. Approximately $25 \%$ of specimens required use of broth to permit inoculation of the blood agar and MEA. Bacterial growth was found in 10 specimens, a contamination rate of $20 \%$. Coagulase negative staphylococci were the commonest organisms (four out of 10), the remainder comprising micrococci, diphtheroids, and two not fully identified. No specimen gave growth with more than one medium. Details are given in Table 1.

\section{Discussion}

This study provides further evidence that the anterior chambers of patients undergoing cataract surgery are often contaminated at the end of the procedure by small numbers of organisms, and that these organisms are commonly skin commensals. It is recognised that contamination may occur during the process of obtaining and culturing samples. The figures obtained therefore represent upper limits which can only be refined by more extensive studies.

As in previous studies, none of our patients developed any complications that could be related to these organisms, which probably stems from their low virulence and/or clearance of the organism from the anterior chamber. The contamination rate of $20 \%$ compares (without statistical significance) with the rate of $24 \%$ found in our previous study of extracapsular surgery, and hence we can state that using our techniques, there is no proved advantage to be gained by using small incision surgery in terms of reducing bacterial contamination of the ocular contents during cataract surgery.

This is the first time, as far as we are aware, that a significant number of cases has been studied comparing the two techniques in this way. Additional comparability is gained by the fact that the same two surgeons who carried out the procedures in the study on extracapsular surgery performed the phacoemulsification surgery, thus reducing some of the many variables entering any study comparing surgical techniques. It is recognised, however, that limitations of sample size in this study mean that a clinically worthwhile reduction (say $50 \%$ ) in contamination rates could have been missed.

Bacterial endophthalmitis remains a real problem despite reduced incidence over recent decades, and greater efforts towards prophylaxis and treatment. Severe damage to sight is the outcome in $40-60 \%$ of cases. The incidence of endophthalmitis after extracapsular surgery is approximately $0 \cdot 1 \%,{ }^{8}$ a better figure than was seen with intracapsular surgery $(0.7 \%)$. This improvement is thought to be largely due to the maintenance of a physical barrier (the posterior capsule and zonules) between the anterior chamber and the privileged culture medium of the vitreous. ${ }^{9} 10$ Various studies have postulated that small incision surgery with phacoemulsification might further reduce the incidence, for reasons outlined previously, and some surgeons have claimed very low incidence for their techniques, but no large scale studies have been published.

It has been shown by DNA analysis techniques that the organisms causing endophthalmitis are commonly the patients' own bacterial flora, ${ }^{11}$ and efforts have been made to reduce the preoperative conjunctival and lash flora. Povidone-iodine conjunctival rinse has been shown to be helpful both in reducing flora and in reducing endophthalmitis, ${ }^{12}$ although preoperative antibiotics appear to be of more limited value. ${ }^{13}$

The mechanism of introduction of these organisms into the eye is of most interest to us with regard to this sturdy. Access may be achieved via the irrigating solutions, instrumentation, the intraocular lens, or via surface fluid reflux. Deeply placed sutures may allow later tracking of organisms into the eye, and inadequate wound closure or vitreous wicks to the wound have been implicated in postoperative infections. ${ }^{14}$ Contaminated irrigation solution has caused epidemic cases, ${ }^{15}$ but should not be a factor routinely. The intraocular lens has received attention and, in particular, polypropylene haptics are an additional risk factor for bacterial adherence. ${ }^{16}$ Sherwood et al postulated that surface fluid reflux via wound margins, demonstrated by fluorescein tracks during irrigation, might wash in the conjunctival flora. ${ }^{2}$ This inflow may be a function of the large unsealed wound in extracapsular surgery and the episodes of low to negative intraocular pressure (causing anterior chamber collapse) often seen in this type of surgery. Small tightly fitting incisions have been correlated with better control of intraocular pressure, and fewer episodes of anterior chamber collapse. ${ }^{17}$ On our observations after instillation of fluorescein during irrigation/aspiration in small incision surgery, there is no obvious inflow. The role of intraocular instrumentation has not received as much investigation, although the intraocular lens has been shown to become 
contaminated by the ocular surface and the operating theatre atmosphere. Because of the additional phacoemulsification measure, intraocular instrumentation time may be increased in this type of surgery, a factor which may offset the supposed benefits of the smaller wound. It is suggested that further study could be made into instrument and intraocular lens contamination, particularly concentrating on episodes of contact with external ocular surfaces, as this is the apparent source of the organisms responsible for endophthalmitis.

Until further evidence supports any particular surgical technique in this regard, prevention of endophthalmitis can best be attempted by the use of occlusive draping, preoperative povidone-iodine, possibly perioperative antibiotics, meticulous surgery, and minimal intraoperative instrumentation.

We should like to acknowledge the help of Mr K P Stannard of the department of ophthalmology and Dr A J Bint of the department of microbiology, Royal Victoria Infirmary, Newcastle-upon-Tyne, for their technical assistance.

1 Chitkara DK, Manners T, Chapman F, Stoddart MG, Hill $D$, Jenkins D. Lack of effect of preoperative norfloxacin $D$, Jenkin on bacterial contamination of anterior chamber aspirates after cataract surgery. Br f Ophthalmol 1994; 78: 772-4

2 Sherwood DR, Rich WJ, Jacob JS, Hart RJ, Fairchild YL. Bacterial contamination of intraocular and extraocular fluids during extracapsular cataract extraction. Eye 1989, 3: $308-12$.

3 Pospisil A, Pospisil F, Dupont MJ, Delbosc B, Montard M Bacterial contamination of the anterior chamber and cataract surgery. 7 Fr Ophtalmol 1993; 16: 10-3.

4 Caldwell DR, Kasti PR, Goh J, Simon J. Povidone-iodine; its' efficacy as a preoperative conjunctival and perioperative preparation Ann Ophthalmol 1984; 16: 577-80.

5 Apt L, Isenberg SJ, Yoshimori R, Spieter A. Outpatient topical use of povidone-iodine in preparing the eye for surgery. Ophthalmology 1989; 96: 289-92.

6 Whitney CR, Anderson RP, Smith MA. Preoperatively administered antibiotics. Their effect on bacterial counts of the eyelids. Arch Ophthalmol 1972; 87: 155

7 Wilbrandt HR, Wilbrandt TH. Evaluation of intraocular pressure fluctuations with differing phacoemulsification pressure huctuations with differing phact Refract Surg 1993; 19: 223-32.

8 Javitt JC, Vitale S, Canner JK, Street DA, Krakauer H McBean AM, et al. National outcomes of cataract extrac tion. Arch Ophthalmol 1991; 109: 1085-9.

9 Beyer TL, Vogler G, Sharma D, O'Donnell FE. Posterio barrier effects of posterior lens capsule in exogenous bacterial endophthalmitis. An experimental primate study. Invest Ophthalmol Vis Sci 1984; 25: 108.

10 Beyer TL, O'Donnell FE, Goncalves V, Singh R. Role of the posterior capsule in the prevention of postoperative bacterial endophthalmitis. Br $\mathcal{F}$ Ophthalmol 1985; 69: 841 .

11 Speaker MG, Milch FA, Shah MK, Eisner W, Kreiswith BN. Role of external bacterial flora in the pathogenesis of acute postoperative endophthalmitis. Ophthalmology 1991; 97: 639-50.

12 Speaker MG, Menikoff JA. Prophylaxis of endophthalmitis with topical povidone-iodine. Ophthalmology 1991; 98 1769-75.

13 Hughes DS, Hill RJ. Infectious endophthalmitis after cataract surgery. Br $\mathcal{F}$ Ophthalmol 1994; 78: 227-32.

14 Irvine WD, Flynn HW, Miller D, Pflugfelder SC. Endophthalmitis caused by gram negative organisms. Arch Ophthalmol 1992; 1110: 1450-4.

15 McCray E, Rampell N, Solomon SL, Bond WJ, Marton WJ, O'Day D. Outbreak of candida parapsilosis endophthalmitis after cataract extraction. $\mathcal{f}$ Clin Microbiol 1986; 24: $625-8$.

16 Dilley PN, Holmes-Sellors PJ. Bacterial adhesion to intraocular lenses. F Cataract Refract Surg 1989; 15: intraocular

17 Vafidis GC, Marsh RJ, Stacey AR. Bacterial contamination of intraocular lens surgery. $\mathrm{Br} \mathcal{F}$ Ophthalmol 1984; 68: 520-3. 